\title{
Analysis of the inequality of people at risk at the regional level
}

\author{
Marina Lesnichaya ${ }^{1 *}$, and Oksana Kolchina ${ }^{1}$ \\ ${ }^{1}$ Southern Federal University, Taganrog, 347922, Russian Federation
}

\begin{abstract}
The phenomenon of poverty occurs in any modern society. The avalanche-like increase of this phenomenon has become the most important problem of social life. Unfortunately, the assessment of the poverty rate is often reduced to the indicator of cost of living, which reflects only the satisfaction of physiological requirements. This indicator is the base of targeted social assistance determination. Therefore, the main condition for providing this type of support is the identification of categories of deprived low-income families. The successful practice of "region's poverty profile building" was implemented In Rostov region. It aimed at identifying low-income population with maximum decomposition of needy population characteristics. The article proposes a mechanism for improving this service by expanding the typology of low-income population, including the "risk" categories, in other words people who receive wages above the minimum of subsistence, but do not have their own property. On the base of statistical analysis, the study proved the need to include this category of households in the register of those who are eligible for compulsory social support by the authorities, which can significantly affect the improvement in their quality of life. Subsequently, it is possible to amend federal legislation and region's poverty profile.
\end{abstract}

Keywords: living standards, cost of living, region's poverty profile

\section{Introduction}

In the context of globalization and integration of countries into world economy, social and humanitarian bonds, it is necessary to strive for the quality of life and living standards declared in the Universal Declaration of Human Rights, the conventions and recommendations of the European Social Charter, the European Code of Social Security. In his address to the Federal Assembly of 21 April 2021 the President of the Russian Federation, Vladimir Putin emphasized that "it is necessary to achieve greater targeting of the provision of social assistance and services. Qualitatively increase the effectiveness of social policy in relation of deprived people, strengthen its impact". In order to achieve this goal, it is necessary for our social legislation to be, first of all, thoroughly analyzed and adjusted. The development of the social assistance system and its provision should be based

\footnotetext{
* Corresponding author: grezinam@yandex.ru
} 
on the principles of targeting and justice. Therefore, the topic of the research is especially relevant.

In modern conditions, the issue of the quality of human potential and social stratification of the population plays a dominating role. Despite the measures implemented by the authorities in the field of social policy, the differentiation of monetary income in the Russian Federation still remains at a high level: the Gini coefficient in 2020 was 0.403 (in 2019 - 0.411), and the decile coefficient of funds was 15.4 times (in $2019-14.5$ times). Economic income inequality, the poverty of the population, and excessive socio-economic stratification of Russian society bring to the forefront the issues of forming effective distribution mechanisms, new measures of social support for the population.

The socio-economical development of regional systems is also closely connected with the high differentiation of the population's income and the issue of poverty. The analysis of the legal acts regulating the formation and implementation of social policy in Russia allows claiming that the powers in the field of social protection in Russia belong largely to the authorities of the Russian Federation subjects. Thus, the Russian Federation subjects in their socio-economic strategies pay close attention to social support for the population in the general measure system, aiming at increasing prosperity and decreasing poverty [1].

\section{Literature review}

Many modern scientists identify poverty as an issue of the modern period of social development and study the processes going on in the social sphere. Various aspects of the influence of economic, social, and demographic policy on the standard of living of the population were studied by Case and Deaton [2], Grinberg and Komolov [3], Kleiner [4], Rutkowski [5], Shevyakov [6], Shcherbakova and Vishnevsky [7], Zakharov [8].

Extremely interesting methods of analyzing the quality of life give unconventional, other than the economic "mainstream," based on neoclassical theories of the work of Nobel laureates Becker [25]. In modern economics, there are quite a lot of methodological approaches to assessing the level and differentiation of the income of the population. Lokshin [9], Migranova [10, 11], Rimashevskaya [11], Safronov and Zubarevich [12], Zharomsky $[10,13]$ have conducted research in this direction.

The effectiveness of various social protection measures and individual instruments of social support for the population is considered by Aizinova [14], Gorina [15], Maleva et al. [16], Krupensky and Kuzina [17], Ovcharova [18], Tsatsura [19].

We can distinguish the work of ISEPN RAS, headed by N.M. Rimashevskaya, in particular collections from the series "Demography and Sociology." The authors Rimashevskaya[23], Zherebin[20], Mozhina, Prokofiev, Toksanbaeva [23,24] in their articles dealt with the problems of determining and measuring poverty, conducted a comparative analysis of poverty in Russia and foreign countries, analyzed differences in living standards and studied the features of consumption and property security of poor families with children. Specialists analyzed the characteristics of living standards and sources of income of single-parent families by Calabihina [22], Rzhanitsyna. Such authoritative researchers as Sinyavskaya, Ovcharova [20], Kuchmaeva [21] and others addressed the topic of living standards of families with children Kuchmaeva [21] et al. Regional work on the poverty of families with children has also appeared [26, 27].

\section{Results}




\subsection{Analysis of the living standard of the population of the Rostov region}

The study of the parameters of socio-economic differentiation of the population will be carried out through the example of the Rostov Region. In this region, in 2020, the value of the Gini coefficient in relation to 2019 varied insignificantly and amounted to 0.390 and 0.400 , respectively. In the Rostov Region, the share of the population with monetary incomes below the subsistence minimum of the total population in 2020 was $13.0 \%$ (in $2019-13.3 \%$ ), which is higher than the average value of this indicator for the Russian Federation as a whole (in $2020-12.1 \%$, and in $2019-12.3 \%$ ).

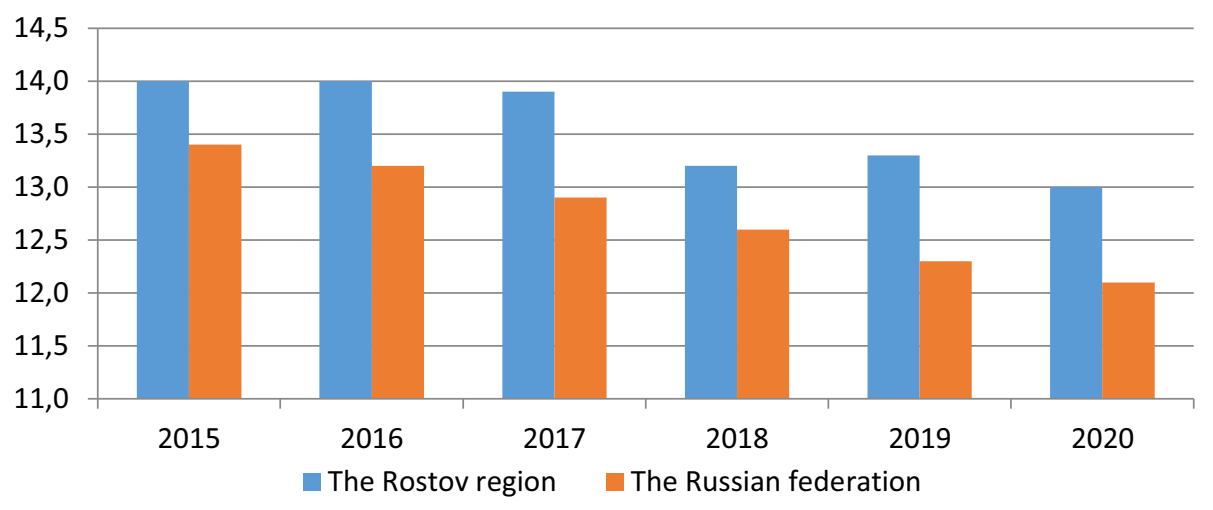

Fig. 1. The number of people with monetary incomes below the subsistence minimum, as a percentage of the total population.

Despite the positive dynamics of an increase in average monetary income indicators and a decrease in the level of poverty, social polarization and concentration of income are maintained. Compared to 2019, there is a redistribution of total income towards a slight decrease in the group with the highest incomes due to an increase in the share of the total income of the remaining four 20 percent groups.

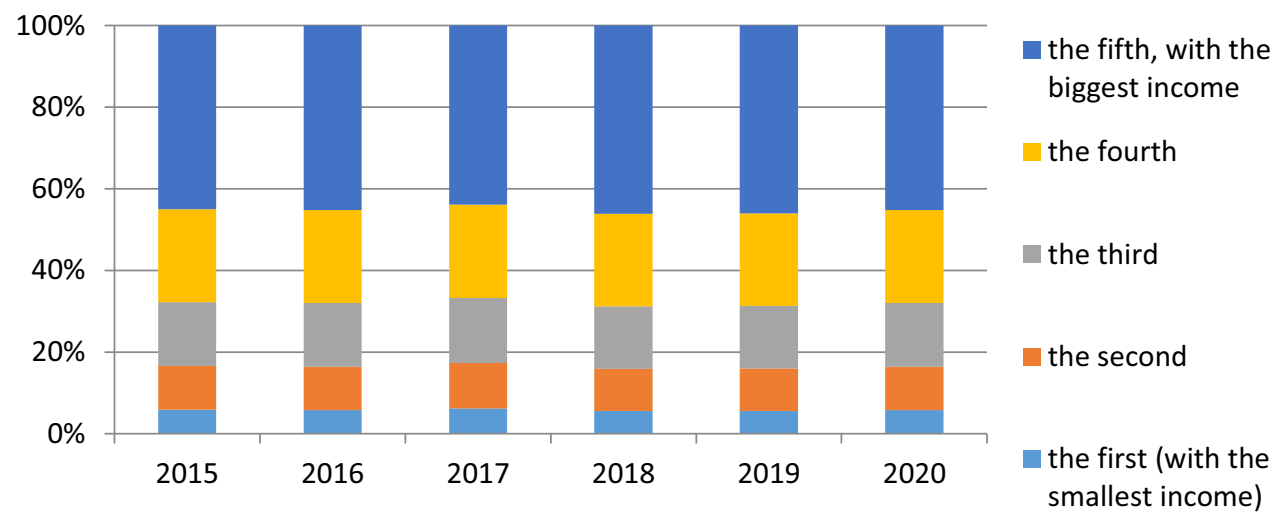

Fig. 2. Redistribution of the total amount of monetary income of the Rostov Region's population by $20 \%$ population groups, as a percentage.

Source: Rosstat (https://gks.ru)

The structure of monetary income of the population in the region in 2015-2019 was stable. In the structure of monetary income, about half of the total amount was the remuneration of employees $(2019-49.3 \%)$, the second element by significance is social 
fees. The analysis of data on the socio-economic state of households allows concluding that, despite the reduction of the lag in the level of wages of those employed in agriculture, the factor of urbanization continues to influence the structure of income of the population. The share of social benefits in the income structure of the population living in urban settlements (19.5\%) is lower than in the income structure of the population living in rural areas $(27.5 \%)$. Considering the fact that there are $32 \%$ of people in the Rostov Region living in the countryside, the matter of forming effective distribution mechanisms is quite relevant.

The poverty indicator helps to determine what amount of addressed aid is needed, so the main criterion of providing such aid is the definition of categories of needy and poor families.

\subsection{Building the region's poverty profile}

In the Rostov Region, there is a working practice in use: "building the region's poverty profile", which is aimed at finding out poor citizens with the maximum decomposition of the needy ones (the practice was supported by the Lipetsk District, the Sakha Republic, and the Nizhny Novgorod Region) (Fig. 3).
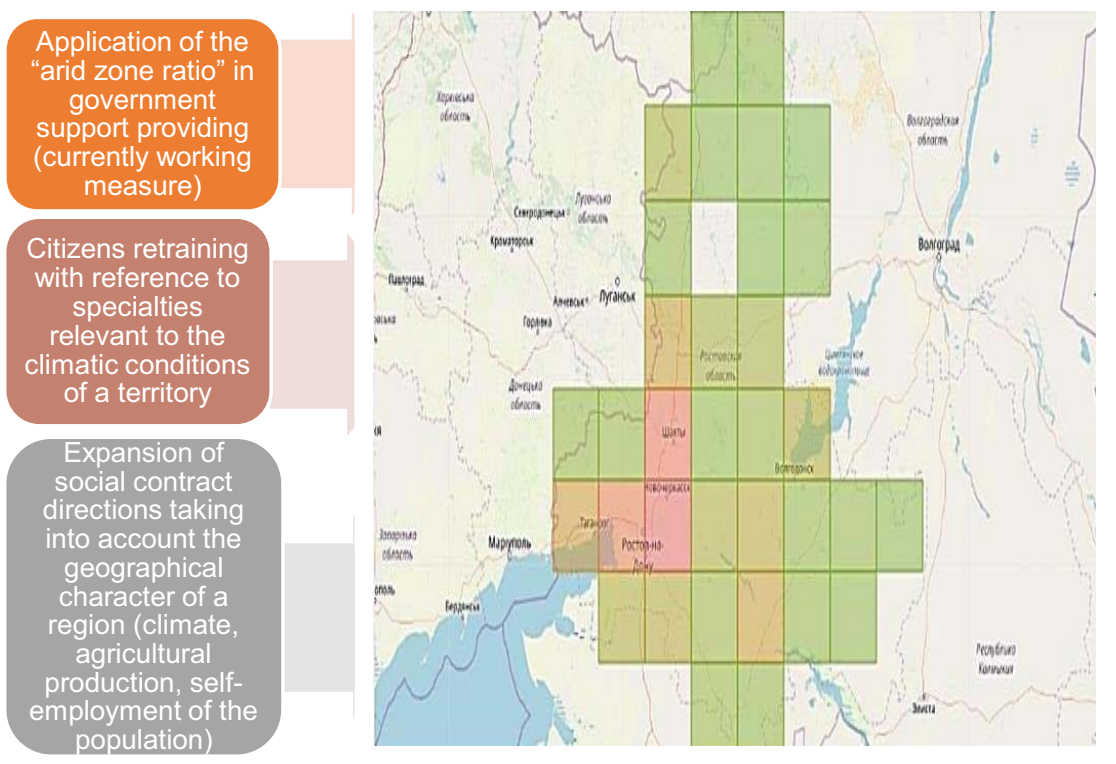

Fig. 3. The Rostov Region's poverty map (the age group of people ranging from 18 to 24 years of age, with children).

Source: Smarteka (https://smarteka.com)

In this regard, improving the methodology for classifying poor families, which is used in the practice, is especially relevant.

The regional law "On targeted social assistance in the Rostov Region" (October 22, 2004 No. 174-ZS) defines the following categories of citizens:

- households or citizens living alone who receive an income below the subsistence minimum established in the Rostov Region per capita;

- households comprising unemployed citizens at the age of retirement and (or) disabled people having the 1 st or 2 nd-degree disability; 
- households that include disabled children who receive an income below one and a half times the subsistence minimum for children in the Rostov Region;

- persons in extreme situations.

According to the normative regular act, one can conclude that people who have an income somewhat higher than the subsistence level cannot count on social fees, though they are identified as risky. So, it is important to know the percentage of people identified as such Table 1.

Table 1. Distribution of total volumes and the volume of the constituent components of monetary income in 2020, the Rostov Region.

\begin{tabular}{|l|c|c|c|c|c|c|}
\hline \multicolumn{1}{|c|}{ Indicators } & $\begin{array}{c}\mathbf{5 0 0 0 . 1} \div \\
\mathbf{7 0 0 0 . 0}\end{array}$ & $\begin{array}{c}\mathbf{7 0 0 0 . 1} \div \\
\mathbf{9 0 0 0 . 0}\end{array}$ & $\begin{array}{c}\mathbf{9 0 0 0 . 1} \div \\
\mathbf{1 2 , 0 0 0 . 0}\end{array}$ & $\begin{array}{c}\mathbf{1 2 , 0 0 0 . 1} \div \\
\mathbf{1 5 , 0 0 0 . 0}\end{array}$ & $\begin{array}{c}\mathbf{1 5 , 0 0 0 . 1} \div \\
\mathbf{2 0 , 0 0 0 . 0}\end{array}$ & $\begin{array}{c}\mathbf{2 0 , 0 0 0 . 1} \div \\
\mathbf{2 5 , 0 0 0 . 0}\end{array}$ \\
\hline Monetary income - total & 0.8 & 1.4 & 4.4 & 6.1 & 10.3 & 10.0 \\
\hline labor income - total & 0.6 & 1.2 & 3.5 & 4.5 & 7.3 & 8.6 \\
\hline property income - total & 1.8 & 2.0 & 6.0 & 4.3 & 14.6 & 4.2 \\
\hline transfers received & 1.5 & 2.3 & 7.4 & 11.6 & 20.3 & 15.4 \\
\hline Social fees, including: & 1.5 & 2.2 & 7.0 & 11.7 & 20.6 & 15.2 \\
\hline $\begin{array}{l}\text { Disposable monetary } \\
\text { income }\end{array}$ & 0.9 & 1.5 & 4.5 & 6.3 & 10.6 & 10.2 \\
\hline
\end{tabular}

\subsection{Calculation of per capita household income 6 decile}

The table shows that in the Rostov Region, $6.7 \%$ of households are below the poverty line and $26 \%$ of households receive income from 12 thousand rubles to 25 thousand rubles, without being able to receive social benefits. However, is the age group of 12-25 so unambiguous, and are there people in it who live lower than the subsistence level? A simple calculation will help to work that out. Let us take, for example, a family of four: two working adults with a wage of 35 thousand rubles and two children over seven years old (that is exactly the amount of children a family must have in order to get out of the demographic crisis), who do not possess their own property. On average, in the urban districts of the Rostov Region, the rent of a one-room apartment (even with violation of the normative values for sq.m. per person), taking into account the cost of utilities, is 10 thousand rubles. The calculation is as follows: $(50,000$ rubles $-10,000$ rubles $) / 4=10,000$ rubles.

Thus, a family receiving the maximum salary of the 5th decile group under the specified conditions automatically falls into the category of "poor", but cannot receive support from the authorities. Let alone households with a smaller level of income. Therefore, the authors deem it necessary to include low-income citizens into the category of poor, the citizens at risk, who possess no property. Unfortunately, the Ministry of Construction and Housing and Communal Services of the Russian Federation does not gather any statistics on the category of citizens, so it is hard to tell the percentage. However, one can consider such an indicator of the existing problem as the amount of households being on the account for house acqusition. 

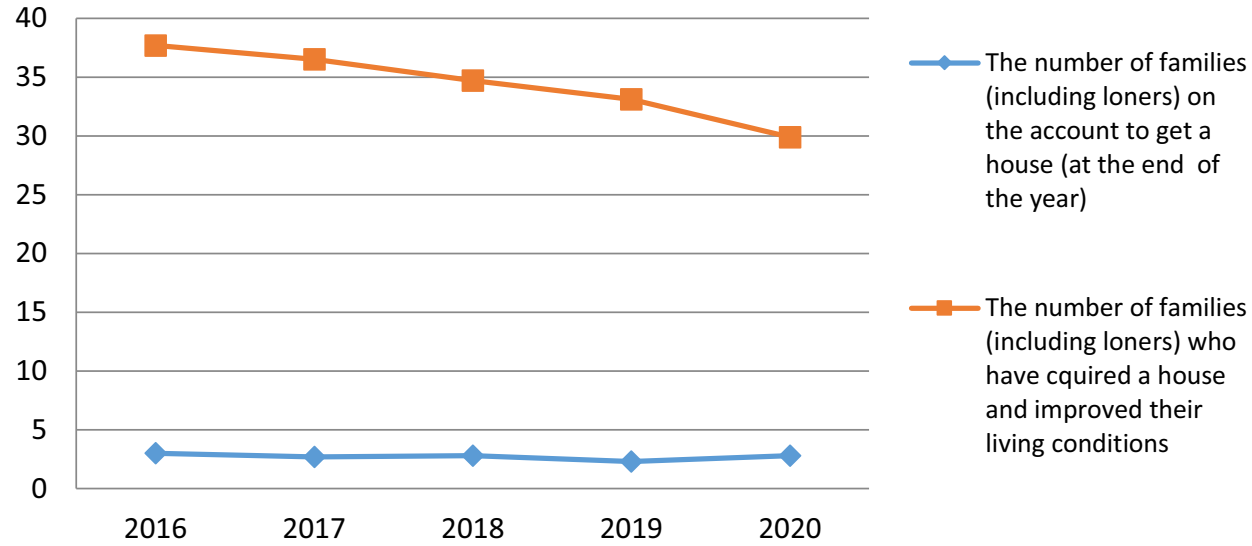

Fig. 4. The number of families on the account to get a house and the ones that have improved their living conditions in the Rostov Region.

There is an interesting fact concerning addressed aid in the Rostov Region. On May 10, 2021, Vladimir Putin signed an order for the assignment of auxiliary payments for children of different ages taking into account the average income of the family per person, but when assigning the payments, the family's property will be necessarily taken into account. That means that if a family has two apartments, they will be refused the assignment of the payment, which is quite fair. The question arises, why does not the Ministry of Labor consider the fact of property absence and the contributions of the "at-risk" population category when assigning the benefit and refers to the subsistence level without even gathering statistics on such sort of indicators? Taking into account the fact that the indicators of average wages in statistical bulletins are calculated taking into account personal income tax, the "net" income of the population for different decile groups is significantly lower than the average. As known, the proportional scale of taxation in combination with social contributions of the population in the Russian Federation leads to an increase in the tax burden on the poor, which significantly reduces the standard of living of more than $50 \%$ of the population (Fig. 5).

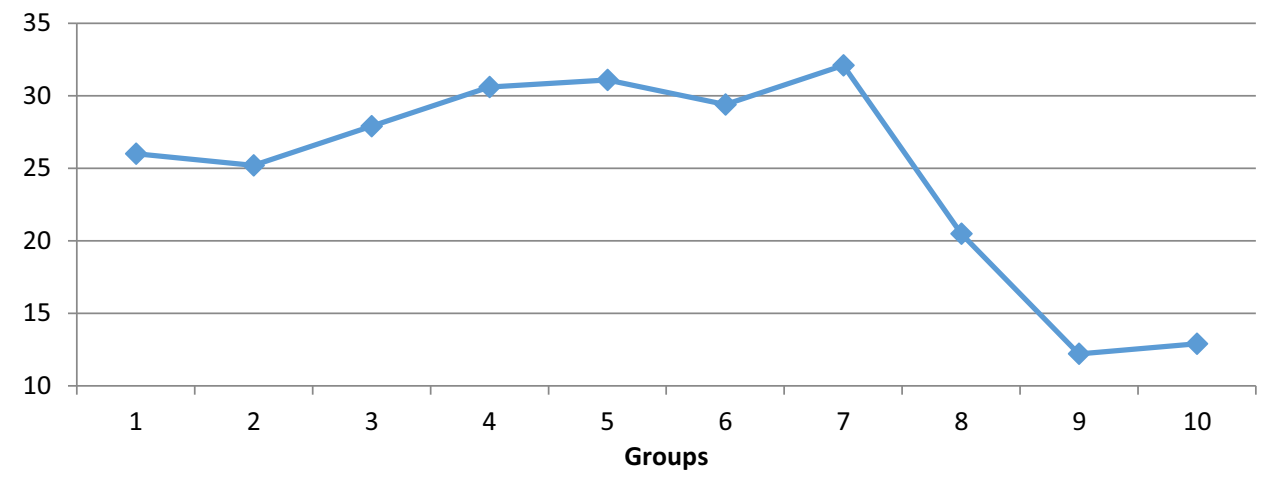

Fig. 5. Taxes per capita as a percentage of per capita monetary income with taxes for 10 decile groups.

One can conclude based on this diagram that in Russia, there is not a "flat" tax system with some elements of a progressive one, but a regressive one instead. With an increase in income, the interest rate decreases, although it is supposed to grow rapidly. Such a paradox arises due to the fact that employees are essentially double-taxed, paying personal income 
$\operatorname{tax}-13 \%$ and a single social tax $-22 \%$, i.e. the employee gives $35 \%$ of his or her income, and the most affluent segments of the population, who receive mainly income from business activities, renting property and dividends, make significantly smaller deductions to the budget. Therefore, in the Russian Federation, the tax burden of the first two groups of deciles is twice as high as that of the latter, which increases the differentiation of the population by income.

\section{Conclusion}

The authors deem it necessary to use the extended typology of poor citizens with maximum decompositions of characteristics of the ones in need and at risk, who do not possess their own property. It is also necessary to make amendments to the federal legislation, the regional law of October 22, 2004 No. 174-ZS "On targeted social assistance in the Rostov Region", and the poverty profile of the region.

The article assessed the real level and structure of poverty of the Rostov region. A detailed analysis of the causes of poverty of citizens and families with children is presented. A mechanism has been proposed to update regional registers of citizens (poverty profile of the Rostov region) with incomes below the subsistence minimum, as well as citizens in the "risk group" - not poor and having an excess of the subsistence minimum, but not owning property (5-6 decile group). A mechanism has been proposed to improve the methodology of typologization of poor families, which allows removing the most massive categories of the population from poverty due to systemic measures.

Since poverty is the cause of the decline in national security, the deterioration of the demographic situation, the degradation of the population, the containment of economic growth, the intensification of social problems in society, the reduction of its scale, especially in the most dangerous, chronic form, is especially important. At the same time, it is necessary to move away from measuring poverty based on the physiological minimum. Modern requirements for state social policy have changed. It should target the general population. The tool considered in the article to measure the standard of living of the population and the proposed methods of its construction can realize the tasks set.

The authorities need to realize that the shift of the gravity center of socio-economic policy towards the optimization of distribution relations has become key for the recovery and prosperity of the country.

Funding: The study was financially supported by the Russian Foundation for Basic Research (RFBR), the project "Developing a concept of improving the living standards and quality of life of the population in the region in the conditions of inter-municipal differentiation, taking into account the economy digitalization" No. 20-010-00815 A.

\section{References}

1. M.A. Lesnichaya, O.A. Kolchina, E.V. Pahomov, H.A. Bageryan, Algorithm of an Automated Analytical Cognitive Modeling Platform for Semi-Structured Management Problems, in Proceedings of the 2021 IEEE Conference of Russian Young Researchers in Electrical and Electronic Engineering, ElConRus, January $26-29$ 2021, St. Petersburg, Russia 2021 (2021)

2. A. Case, A. Deaton, Deaths of Despair and the Future of Capitalism (2020)

3. R.S. Grinberg, O.O. Komolov, Matters of Political Economy, 4(24), 68-82 (2020)

4. G.B. Kleiner, Economic Revival of Russia, 2(64), 59-69 (2020)

5. M. Rutkowski, Finance \& Development, 55(4), 10-13 (2018) 
6. A.Yu. Shevyakov, Myths and Reality of Social Policy (Moscow, ISESP RAS, 2011)

7. A. Vishnevsky, E. Shcherbakova, Russian Journal of Economics, 4, 229-248 (2018)

8. S.V. Zakharov, Population, 37, 209-243 (2019)

9. M. Lokshin, Policy Research Working Paper, 9005 (2019)

10. L.A. Migranova, V.S. Zharomsky, Population, 23, 26-39 (2020)

11. N.M. Rimashevskaya, L.A. Migranova, Population, 3, 17-33 (2016)

12. N.V. Zubarevich, S.G. Safronov, Russian Historical Academy News, the Geographic Series, 5, 3-17 (2019)

13. V.S. Zharomsky, Population, 22, 92-105 (2019)

14. I.M. Aizinova, The Problems of Forecasting, 4(181), 16-28 (2020)

15. E.A. Gorina, Journal of Social Policy Research, 17, 163-176 (2019)

16. T.M. Maleva, E.E. Grishina, A.Ya. Burdyak, Economic Issues, 12, 24-40 (2020)

17. O.E. Kuzina, N.A. Krupensky, Economic Issues, 11, 85-104 (2018)

18. L.N. Ovcharova, E.A. Gorina, Economic Issues, 3, 5-21 (2017)

19. E.E. Grishina, E.A. Tsatsura, The Economic Development of Russia, 25, 65-67 (2018)

20. L.N. Ovcharova, A.Ya. Burdyak, A.I. Pishnyak, D.O. Popova, R.I. Popova, A.M. Liberal, Mission Foundation. 105- 125 (2018)

21. O.V. Kuchmaeva, M.G. Kuchmaev, O.L. Petryakova, Mutual action of family and society: features and prospects. M.: GASK, 198-212 (2019)

22. I.E. Kalabikhina, Family in Russia, 1-2, 166-181. (2020)

23. I.I. Korchagina, Journal of institutional studies, 1, 68-78 (2012)

24. I.I. Korchagina., L.M. Prokofiev, R.I. Popova, Yu.V. Filojnenko, E.V. Fursa, People's settlement, 1, (2015)

25. G.S. Becker, Kyklos, 3 (2020)

26. GINI index. World Bank. URL: https://data.worldbank.org/ (2020)

27. Global wealth report 2019. Credit Suisse Research Institute. URL: https://www.creditsuisse.com/about-us/en/reports-research/global-wealth-report.html (2020) 